Article

\title{
Simulation of Syngas Production from Lignin Using Guaiacol as a Model Compound
}

\author{
Nancy Eloísa Rodríguez-Olalde ${ }^{1}$, Erick Alejandro Mendoza-Chávez ${ }^{1}$, \\ Agustín Jaime Castro-Montoya ${ }^{1, *}$, Jaime Saucedo-Luna ${ }^{1}$, Rafael Maya-Yescas ${ }^{1}$, \\ José Guadalupe Rutiaga-Quiñones ${ }^{2}$ and José María Ponce Ortega ${ }^{1}$
}

1 Facultad de Ingeniería Química, Universidad Michoacana de San Nicolás de Hidalgo. Edificio "V1", Ciudad Universitaria, 58060, Morelia, Michoacán, Mexico;

E-Mails: neloisanancy@gmail.com (N.E.R.-O.); alejandhro@hotmail.com (E.A.M.-C.); saucedo1@hotmail.com (J.S.-L.); rmayay@umich.mx (R.M.-Y.); jmponce@umich.mx (J.M.P.O.)

2 Facultad de Ingeniería en Tecnología de la Madera, Universidad Michoacana de San Nicolás de Hidalgo. Edificio “D”, Ciudad Universitaria, 58060, Morelia, Michoacán, Mexico;

E-Mail: jrutiaga@yahoo.com.mx

* Author to whom correspondence should be addressed; E-Mail: ajcastro@umich.mx; Tel.: +52-443-327-3584; Fax: +52-443-316-7176.

Academic Editor: Mehrdad Massoudi

Received: 13 May 2015 / Accepted: 17 June 2015 / Published: 30 June 2015

\begin{abstract}
Lignin is an abundant component in biomass that can be used a feedstock for producing several value-added products, including biofuels. However, lignin is a complex molecule (involving in its structure three types of phenylpropane units: coumaryl, coniferyl and sinapyl), which is difficult to implement in any process simulation task. The lignin from softwood is formed mainly by coniferyl units; therefore, in this work the use of the guaiacol molecule to model softwood lignin in the simulation of the syngas process $\left(\mathrm{H}_{2}+\mathrm{CO}\right)$ is proposed. A Gibbs reactor in ASPEN PLUS ${ }^{\circledR}$ was feed with ratios of water and guaiacol from 0.5 to 20 . The pressure was varied from 0.05 to $1.01 \mathrm{MPa}$ and the temperature in the range of $200-3200{ }^{\circ} \mathrm{C} . \mathrm{H}_{2}, \mathrm{CO}, \mathrm{CO}_{2}, \mathrm{CH}_{4}, \mathrm{O}_{2}$ and $\mathrm{C}$ as graphite were considered in the output stream. The pressure, temperature and ratio water/guaiacol conditions for syngas production for different $\mathrm{H}_{2} / \mathrm{CO}$ ratio are discussed. The obtained results allow to determine the operating conditions to improve the syngas production and show that $\mathrm{C}$ as graphite and water decomposition can be avoided.
\end{abstract}


Keywords: gasification of lignin; guaiacol as lignin model compound; syngas production

\section{Introduction}

Lignin is one of the most abundant biomass components. It exhibits complex structures that depending on the wood type can include a mixture of the following primary phenylpropane units: cuomaryl, coniferyl and sinapyl. In the lignin from softwood, the amount of coniferyl units is about $90 \%-95 \%$, the sinapyl units from 5\% to $10 \%$ and there are no coumaryl units [1]. Some compounds, such as guaiacol, anisole, and diphenyl ether have been used as a representative structures of lignin for simulation and experimental studies [2-4]. In others works, the lignin is specified as a non-conventional component using ultimate and proximate analysis [5,6]. Guaiacol comes from coniferyl alcohol, and it can be used as a softwood lignin model compound to analyze biomass decomposition processes such as pyrolysis and gasification, among others. Figures 1 and 2 show the structural formulas for guaiacol and lignin [7], respectively. It should be noticed that the guaiacol structure frequently appears in the structure of lignin, so this compound represents a large portion of it and it could be considered representative of lignin.

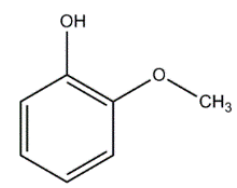

Figure 1. The structure of guaiacol, the lignin model compound used in this study.

Lignin has a high potential for producing biofuels and aromatic compounds. The technology for using lignin as a raw material has not been developed much in comparison with technologies to process polysaccharides and, in all cases, lignin is a sub-product of these processes, which opens an opportunity to consider it as a feedstock to downstream process that add value to this important renewable polymer. It can be noted that carbon materials increase the possibilities of mass/energy generation [8], and syngas production is one of them. Syngas is a mixture of hydrogen and carbon monoxide $\left(\mathrm{H}_{2}+\mathrm{CO}\right)$, which can be obtained by gasification of different materials. Currently, several options like natural gas [9], ethanol [10] and glycerol [11] have been studied to produce syngas or hydrogen in several processes [12,13]. Rostrup-Nielsen proposed a syngas cycle that involves steam reforming and gasification to produce syngas from complex materials andFisher-Tropsch synthesis to obtain complex materials [14]. Another interesting option is to consider biomass [15], such as lignin, as a raw material to produce energy in an integral way $[16,17]$.

Process simulation has been used to determine the best options and operating conditions for producing biofuels [5,6,18-26], particularly the software ASPEN PLUS ${ }^{\circledR}$ (Aspen Technology, Inc., Bedford, MA, USA) has been widely used. However, the models used for lignin have oversimplified the process. To produce syngas (smaller molecules that can be obtained) from biomass the simplified models are good, but for bigger molecules (phenol, benzene, etc.) is necessary to use the lignin chemical structure or a model compound. 


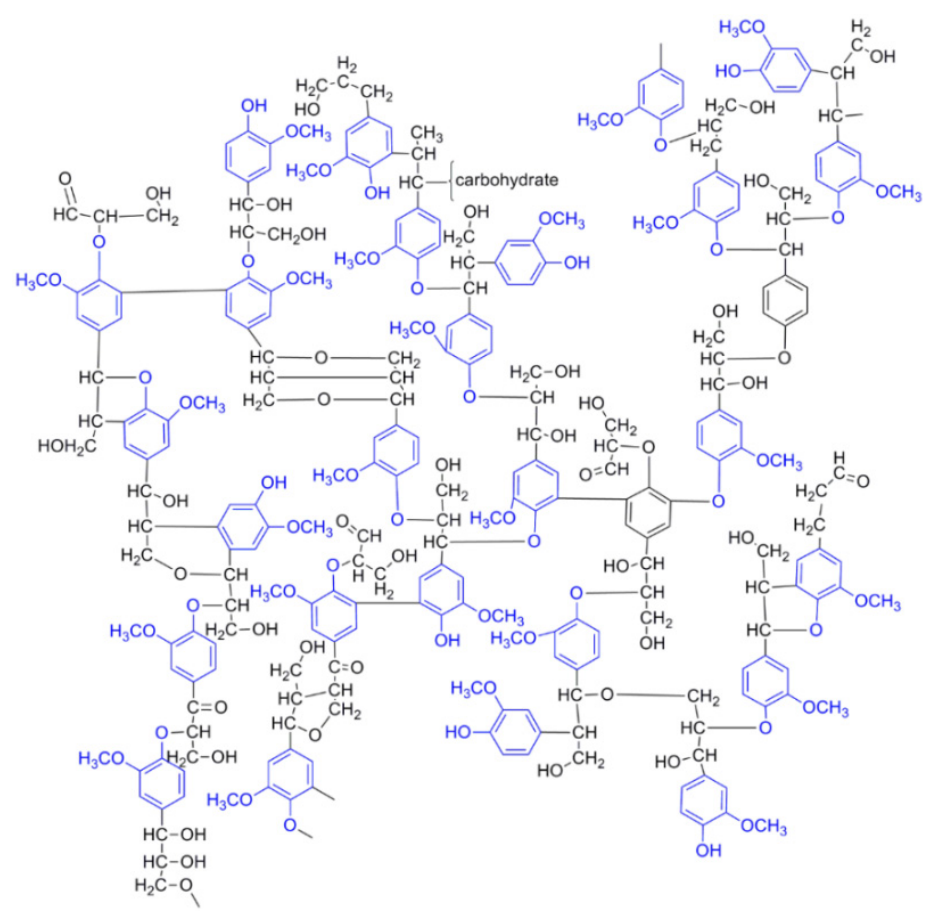

Figure 2. Structure in softwood lignin.

Therefore, in this work there is proposed to use the molecule of guaiacol, which has a $\mathrm{H} / \mathrm{C}$ and $\mathrm{O} / \mathrm{C}$ ratio in the range reported in other studies [20], as a lignin model during the simulation of the gasification process of softwood. This will serve as a starting point that will surely culminate in the use of models very close to the actual chemical structure of lignin, so that research can be performed by process simulators for processing into intermediate products with high added value and production chain initiators, all under the concept of biorefineries.

\section{Materials and Methods}

A Gibbs reactor was implemented in the software ASPEN PLUS ${ }^{\circledR}$ for the syngas production, which was fed with water $(w)$ and guaiacol $(g)$. The ratio water/guaiacol $(w / g)$ was varied from 0.25 to 20 , four levels of pressure were tested $(0.05,0.1,0.51$ and $1.01 \mathrm{MPa})$ and the analyzed temperature range was from 200 to $3200{ }^{\circ} \mathrm{C}$. We propose Reaction (1) as the main gasification reaction:

$$
\mathrm{C}_{7} \mathrm{H}_{8} \mathrm{O}_{2(\mathrm{~g})}+5 \mathrm{H}_{2} \mathrm{O}_{(\mathrm{g})} \rightarrow 7 \mathrm{CO}_{(\mathrm{g})}+9 \mathrm{H}_{2(\mathrm{~g})}, \Delta \mathrm{H}_{298 \mathrm{~K}}=682 \mathrm{~kJ} / \mathrm{mol}
$$

The following parallel reactions are also involved, in general, these describe the main pathways to obtain the products proposed:

$$
\begin{gathered}
\mathrm{C}_{7} \mathrm{H}_{8} \mathrm{O}_{2(g)}+12 \mathrm{H}_{2} \mathrm{O}_{(g)} \rightarrow 7 \mathrm{CO}_{2(g)}+16 \mathrm{H}_{2(g)}, \Delta H_{298 \mathrm{~K}}=395 \mathrm{~kJ} / \mathrm{mol} \\
\mathrm{CO}_{(g)}+\mathrm{H}_{2} \mathrm{O}_{(g)} \rightarrow \mathrm{CO}_{2(g)}+\mathrm{H}_{2(g)}, \Delta H_{298 \mathrm{~K}}=-41 \mathrm{~kJ} / \mathrm{mol} \\
\mathrm{CO}_{(g)}+3 \mathrm{H}_{2(g)} \rightarrow \mathrm{CH}_{4(g)}+\mathrm{H}_{2} \mathrm{O}_{(g)}, \Delta H_{298 \mathrm{~K}}=-205.5 \mathrm{~kJ} / \mathrm{mol} \\
\mathrm{CO}_{2(g)}+4 \mathrm{H}_{2(g)} \rightarrow \mathrm{CH}_{4(g)}+2 \mathrm{H}_{2} \mathrm{O}_{(g)}, \Delta H_{298 \mathrm{~K}}=-164.5 \mathrm{~kJ} / \mathrm{mol} \\
2 \mathrm{CO}_{(g)} \rightarrow 2 \mathrm{C}_{(s)}+\mathrm{O}_{2(g)}, \Delta H_{298 \mathrm{~K}}=222 \mathrm{~kJ} / \mathrm{mol} \\
\mathrm{CO}_{2(g)} \rightarrow C_{(s)}+\mathrm{O}_{2(g)}, \Delta H_{298 \mathrm{~K}}=394 \mathrm{~kJ} / \mathrm{mol}
\end{gathered}
$$




$$
\begin{gathered}
\mathrm{CH}_{4(g)} \rightarrow \mathrm{C}_{(s)}+2 \mathrm{H}_{2(g)}, \Delta H_{298 \mathrm{~K}}=74.5 \mathrm{~kJ} / \mathrm{mol} \\
2 \mathrm{CO}_{(g)} \rightarrow \mathrm{CO}_{2(g)}+C_{(s)}, \Delta H_{298 \mathrm{~K}}=-172 \mathrm{~kJ} / \mathrm{mol} \\
2 \mathrm{H}_{2} \mathrm{O}_{(g)} \rightarrow \mathrm{O}_{2(g)}+2 \mathrm{H}_{2(g)}, \Delta H_{298 \mathrm{~K}}=484 \mathrm{~kJ} / \mathrm{mol}
\end{gathered}
$$

The Gibbs free energy is a thermodynamic variable used to identify the chemical equilibrium in a system, its global minimization allows identifying the amount of substances present in the process. If the system contains $n$ components, the molar fraction of component $i$ is $x_{i}$; the change of Gibbs free energy, $g_{s y s}$, in the system is defined in Equation (11):

$$
g_{s y s}=\sum x_{i}+R T \sum x_{i} \ln x_{i}
$$

If Equation (11) is derived with respect to $x_{a}$ and if only two components are present (a and b), the change of the free energy of the system with respect to each component is obtained by Equation (12):

$$
\frac{d g_{s y s}}{d x_{a}}=g_{a}^{\circ}-g_{b}^{\circ}+R T \ln \frac{x_{a}}{1-x_{a}}
$$

Here, $g_{a}^{\circ}$ corresponds to the standard Gibbs free energy for the pure component $a, R$ is the universal gas constant and $T$ is the temperature for the system. The minimum free energy of a system is found when Equation (12) is equal to zero and by solving the system it is possible to find the equilibrium composition [27], which gives the products and the amount of each one that is present.

\section{Results and Discussion}

The effects of pressure, temperature and water/guaiacol ratio $(w / g)$ on the syngas production were studied in this work. The best operating conditions that improve the $\mathrm{H}_{2}$ and $\mathrm{CO}$ (syngas) production for gasification were determined. This process was analyzed at $0.05,0.1,0.51$ and $1.01 \mathrm{MPa}$, whereby it was found that the syngas production decreases when the pressure increases and increases with temperature until a maximum is reached and then it drops. The best yields were obtained at the pressures of 0.05 and $0.1 \mathrm{MPa}$, where the maximum $\mathrm{H}_{2}$ productions were $1300 \mathrm{~mol} / \mathrm{h}$ at $0.05 \mathrm{MPa}$ and $1289 \mathrm{~mol} / \mathrm{h}$ at $0.1 \mathrm{MPa}$ the Figure 3a,b show the results. For $0.51 \mathrm{MPa}$ the production was 1109 and $930 \mathrm{~mol} / \mathrm{h}$ for $1.01 \mathrm{MPa}$, the yield were lower at same temperature $\left(700^{\circ} \mathrm{C}\right)$. It should be noticed in Figure $3 \mathrm{a}, \mathrm{b}$ that the $\mathrm{H}_{2}$ production exhibits a maximum at around $700{ }^{\circ} \mathrm{C}$, which can be explained by the gasification process, and another one around $3200{ }^{\circ} \mathrm{C}$ that confirms the thermal decomposition of water, as it was reported previously [28-31] and is proposed in Reaction (10). Figure 3c,d are for the case of carbon monoxide production at pressures of 0.05 and $0.1 \mathrm{MPa}$ and exhibit the same highest value $(700 \mathrm{~mol} / \mathrm{h})$ at both pressures. From these results, the pressure of $0.1 \mathrm{MPa}$ is the one selected for the analysis, which corresponds to the atmospheric pressure. The ratio $w / g$ that allows obtaining the highest values for hydrogen production is from 15 to 20 . 

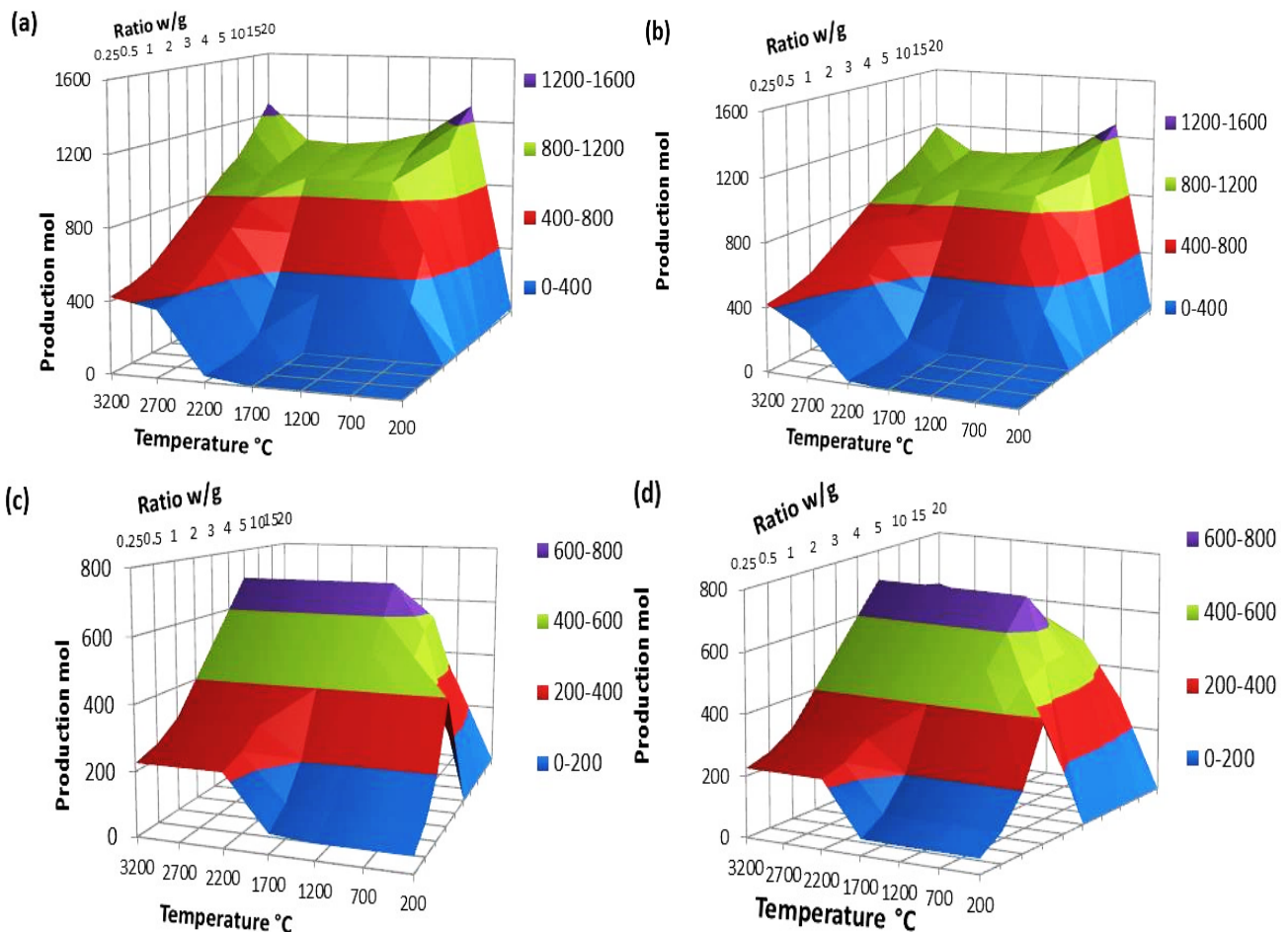

(d)

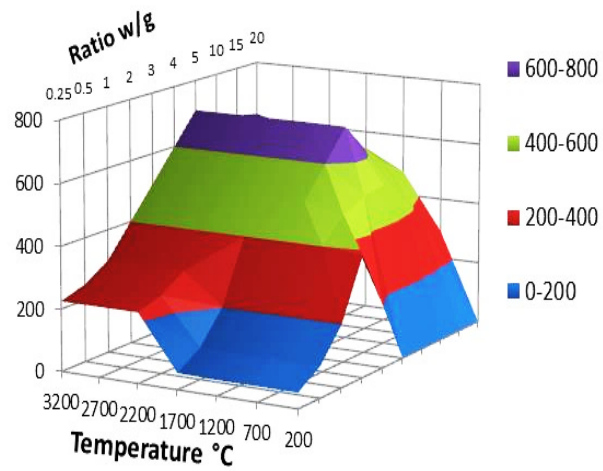

Figure 3. Production of $\mathrm{H}_{2}$ at (a) 0.05 and (b) $0.1 \mathrm{MPa}$; production of $\mathrm{CO}$ at (c) 0.05 and (d) $0.1 \mathrm{MPa}$.

On the other hand, the oxygen production increases at high temperatures $\left(2200\right.$ to $\left.3200{ }^{\circ} \mathrm{C}\right)$, which is shown in Figure 4a; this is consistent with the water decomposition area, Reaction (10). Additionally, the carbon formation as graphite [10,11], Reactions (6)-(8), has to be avoided because it can cause troubles in the processing, methane is necessary in Reaction (8) and at high temperature methane is not present (Figure 5c); therefore, according with the results shown in Figure 4b, the operating conditions have to be chosen as $0.1 \mathrm{MPa}, 15-20 \mathrm{w} / \mathrm{g}$ ratio and $300-1200^{\circ} \mathrm{C}$ as in this zone carbon as graphite is absent.
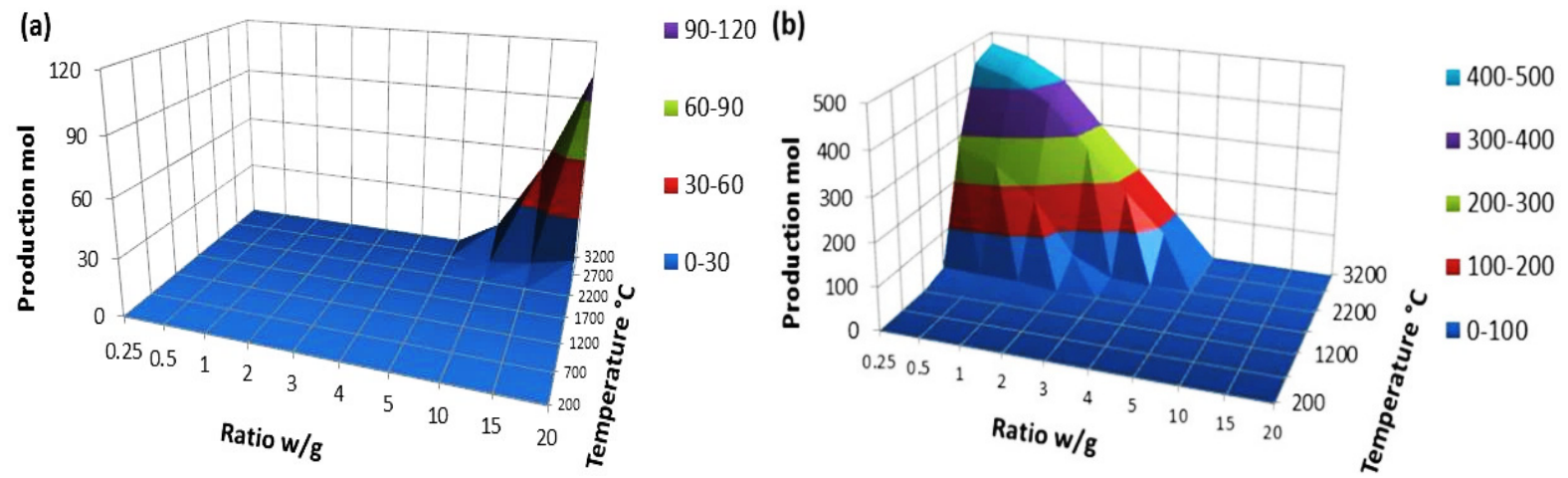

Figure 4. Production of (a) oxygen and (b) carbon as graphite at $0.1 \mathrm{MPa}$.

The hydrogen production increases proportionally with the $w / g$ ratio and the temperature up to $700{ }^{\circ} \mathrm{C}$ and until $1000{ }^{\circ} \mathrm{C}$. The maximum hydrogen production was obtained at $700{ }^{\circ} \mathrm{C}$ and $w / g$ ratio of 20 , Figure 5a shows that when the temperature continues increasing the hydrogen production drops. This can be because the Reaction (3) is inverted to reach equilibrium contributing to the consumption of 
carbon dioxide as shown in Figure 5c and on the other hand Reaction (8) is not present because methane is absent up to $700{ }^{\circ} \mathrm{C}$ as shown in Figure $5 \mathrm{~d}$. It should be noted that other processes for hydrogen production have been reported [11] using temperatures of around $900-1000 \mathrm{~K}\left(627-727^{\circ} \mathrm{C}\right)$ and also the pyrolysis process for hydrogen production is carried out around $700{ }^{\circ} \mathrm{C}[13,18]$.
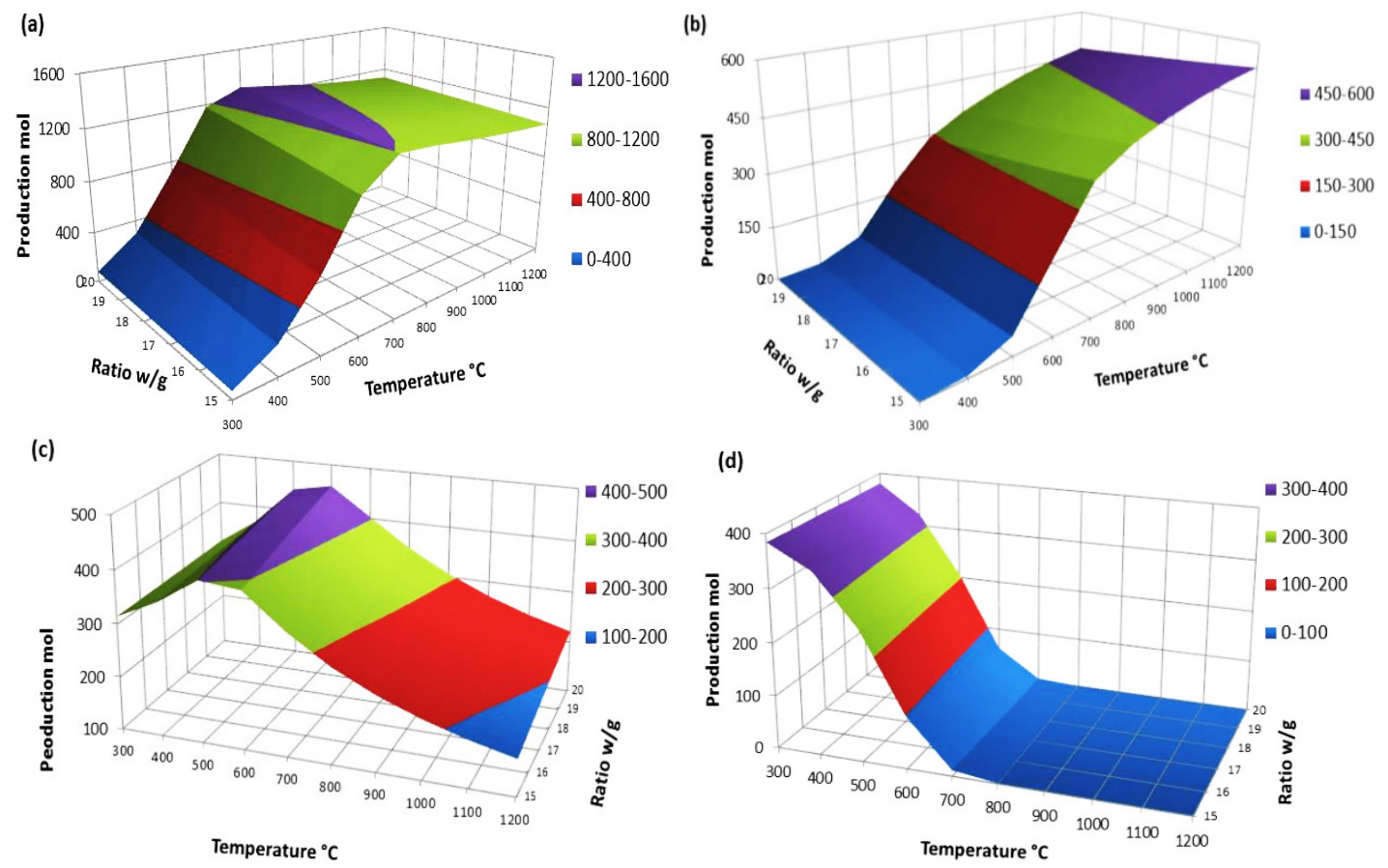

Figure 5. Mol production of (a) hydrogen, (b) carbon monoxide, (c) carbon dioxide and (d) methane at $0.1 \mathrm{MPa}$.

The carbon monoxide production increases proportionally with the temperature and inversely with the $w / g$ ratio. For the temperature range from 300 to $1200{ }^{\circ} \mathrm{C}$, the maximum $\mathrm{CO}$ production can be reached at $1200^{\circ} \mathrm{C}$ and $w / g$ ratios from 15 to 18 (see Figure 5b). It is important to note that the conditions under which the $\mathrm{CO}$ production is maximum are different for the hydrogen production, so the $\mathrm{H}_{2} / \mathrm{CO}$ mole ratio in syngas has to be observed as a response variable; this will be discussed later.

The $\mathrm{CO}_{2}$ production exhibits a maximum at about $600^{\circ} \mathrm{C}$ and then it decreases inversely proportional to the temperature; meanwhile, it is directly proportional to the $w / g$ ratio (see Figure $5 \mathrm{c}$ ). These results are consistent with the literature that establishes that at about $550{ }^{\circ} \mathrm{C}$ the steam reforming process yields the maximum $\mathrm{CO}_{2}$ production [10,12]; for this analysis, the maximum production is obtained at $500-600{ }^{\circ} \mathrm{C}$ and with $w / g$ ratios of 16 to 20 . The proposed Reactions (2), (3) and (9) produce $\mathrm{CO}_{2}$, but Reaction (9) is present when carbon is in the system as graphite, and as Figure $4 \mathrm{~b}$ has shown, this is possible for $w / g$ ratios lower than 5 and in this case the $w / g$ ratio is 20 .

Figure $5 \mathrm{~d}$ shows that at low temperatures the production of methane is high so Reactions (4) and (5) are present. Methane is the only substance that has hydrogen in its structure, so if the hydrogen production increases the methane one decreases; the maximum production of hydrogen is observed in Figure $5 \mathrm{a}$ at $700{ }^{\circ} \mathrm{C}$, where the production of methane is close to zero $[10,12]$ as shown in Figure $5 \mathrm{~d}$. As the Reactions (1)-(3) and (8) have hydrogen as product it can be proposed that these reactions are present until $700{ }^{\circ} \mathrm{C}$, and even that Reaction (10), the water decomposition reaction present at the highest 
temperature has hydrogen as a product. Additionally, it is possible to see that the methane production is independent of the $w / g$ ratio, as the methane production at low and high $w / g$ ratio values is the same.

The maximum water consumption is at temperatures of $600-700{ }^{\circ} \mathrm{C}$ and a $w / g$ ratio of 20 , which is shown in Figure 6a; this evidence supports the assumption that the $\mathrm{H}_{2}$ and $\mathrm{CO}_{2}$ production is carried out by the Reactions (1)-(3), which are present under these conditions. Figure $6 \mathrm{~b}$ shows the other area in which the water consumption increases due to the water decomposition.
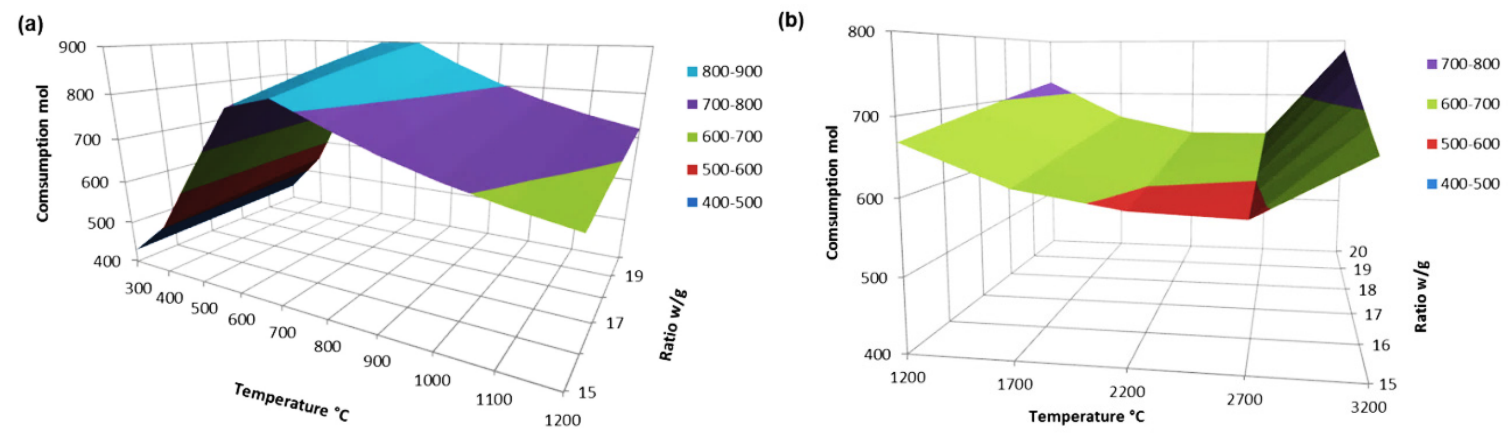

Figure 6. Water consumption at $0.1 \mathrm{MPa}$ from (a) 300 to $1200{ }^{\circ} \mathrm{C}$ and (b) 1200 to $3200{ }^{\circ} \mathrm{C}$.

The productions of $\mathrm{H}_{2}, \mathrm{CO}, \mathrm{CO}_{2}, \mathrm{CH}_{4}, \mathrm{O}_{2}$ and $\mathrm{C}$ in the guaiacol gasification at different temperature conditions are shown in Figure $7 \mathrm{a}, \mathrm{b}$. If producing syngas $\left(\mathrm{CO}+\mathrm{H}_{2}\right)$ is the target, it is important to convert all the carbon to $\mathrm{CO}$ and to minimize the $\mathrm{CH}_{4}$ formation [17]; this condition is reached at a pressure of $0.1 \mathrm{MPa}$, a $w / g$ ratio of 20 and temperatures of $700-1200{ }^{\circ} \mathrm{C}$ (see Figure 7). In Figure $7 \mathrm{~b}$, it can be observed that the water decomposition is starting at $2700{ }^{\circ} \mathrm{C}$, and at $3200{ }^{\circ} \mathrm{C}$ the oxygen presence and hydrogen increase are clear.
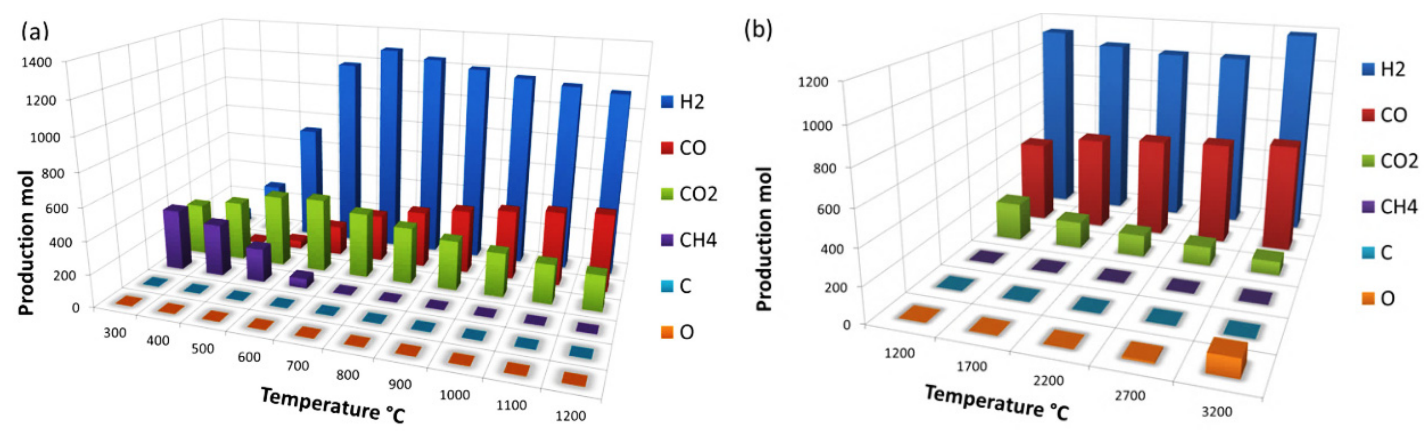

Figure 7. Production of substances from (a) $300-1200{ }^{\circ} \mathrm{C}$ and (b) $1200-3200{ }^{\circ} \mathrm{C}$ at $0.1 \mathrm{MPa}$ and ratio $w / g 20$.

Syngas is the raw material for several processes including the Fisher-Tropsch synthesis, where there are different building blocks according with the $\mathrm{H}_{2} / \mathrm{CO}$ ratio, as air gasification it is lower or equal to 1 , a value higher than 1 is obtained with steam gasification and it is ideal for liquid hydrocarbons, a common target ratio is $2[14,17]$. Depending on the operating temperature, different $\mathrm{H}_{2} / \mathrm{CO}$ ratios are obtained for the syngas process (see Figure 8), from $800{ }^{\circ} \mathrm{C}$ the $\mathrm{H}_{2} / \mathrm{CO}$ ratios are from 2 to 3.5 , which is similar to those obtained with natural gas technologies [9]. If it is decided to maximize the $\mathrm{H}_{2} / \mathrm{CO}$ ratio, the optimum temperature is $700{ }^{\circ} \mathrm{C}$, pressure $0.1 \mathrm{MPa}$ and ratio $w / g 20$; the energy required for this conditions is $350.87 \mathrm{GJ} / \mathrm{h}$. 


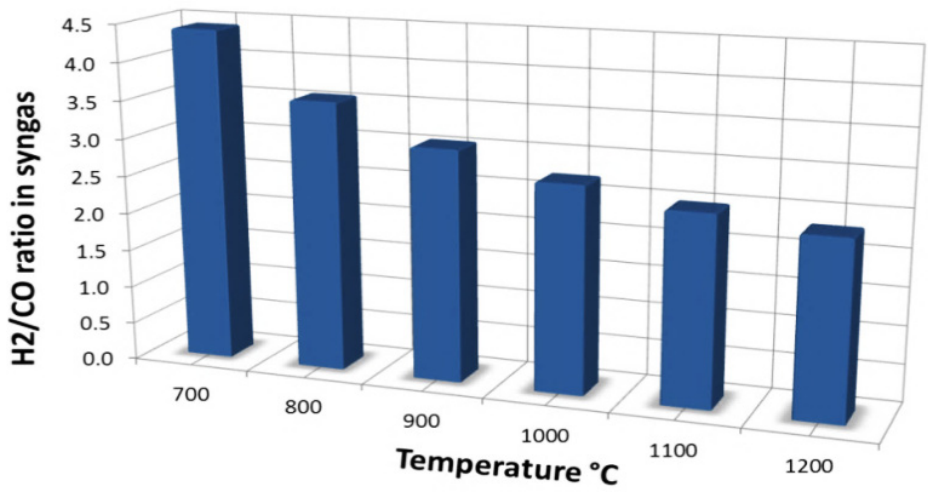

Figure 8. The $\mathrm{H}_{2} / \mathrm{CO}$ ratio in syngas value at $0.1 \mathrm{MPa}$, ratio $w / g 20$ and different temperatures.

\section{Conclusions}

The syngas production process from water and lignin modeled as guaiacol based on the Gibbs free energy was proposed for the first time in this work. The effects of pressure, temperature and $w / g$ ratio were studied. Pressure values above 0.1 MPa decrease the syngas production and lower values do not significantly increase its production. The $w / g$ ratio that lets one obtain higher hydrogen production was from 15 to 20 . Temperatures in the range of $300-1200{ }^{\circ} \mathrm{C}$ allow obtaining different amounts of $\mathrm{H}_{2}, \mathrm{CO}$, $\mathrm{CO}_{2}, \mathrm{CH}_{4}$ without water decomposition and in the absence of carbon as graphite. The ratio $w / g 20$, $0.1 \mathrm{MPa}$ and temperature from $700-1200{ }^{\circ} \mathrm{C}$ enables the production of syngas with $\mathrm{H}_{2} / \mathrm{CO}$ ratios from 4.4 to 2.3. The water decomposition region was identified at temperatures from 2200 to $3200{ }^{\circ} \mathrm{C}$. The maximum hydrogen production was observed at $700^{\circ} \mathrm{C}$ and at this point the methane was practically absent. If water was the limiting reactant at temperatures higher than $1200{ }^{\circ} \mathrm{C}$, graphite formation was observed. This work contributes to the knowledge needed to use biomass in an integrated way for the production of biofuels and high molecular weight compounds.

\section{Acknowledgments}

Nancy Eloísa Rodríguez-Olalde and Erick Alejandro Mendoza-Chávez would like to thank to Consejo Nacional de Ciencia y Tecnología (CONACYT) for their scholarship.

\section{Author Contributions}

The authors contributed to integrate this manuscript as following. Nancy Eloísa Rodríguez-Olalde and Erick Alejandro Mendoza-Chávez developed the model, did the simulation and wrote the manuscript. Jose Guadalupe Rutiaga-Quiñones, Jaime Saucedo-Luna and Agustín Jaime Castro-Montoya designed the study and reviewed the results. José María Ponce-Ortega and Rafael Maya-Yescas reviewed the structure of the manuscript and helped to analyze the results.

\section{Conflicts of Interest}

The authors declare no conflict of interest. 


\section{References}

1. Azadi, P.; Inderwildi, O.R.; Farnood, R.; King, D.A. Liquid fuels, hydrogen and chemicals from lignin: A critical review. Renew. Sustain. Energy. Rev. 2013, 21, 506-523.

2. Wahyudiono; Sasaki, M.; Goto, M. Thermal decomposition of guaiacol in sub- and supercritical water and its kinetic analysis. J. Mater. Cycles Waste Manag. 2011, 13, 68-79.

3. Wu, X.; Fu, J.; Lu, X. Kinetics and mechanism of hydrothermal decomposition of lignin model compounds. Ind. Eng. Chem. Res. 2013, 52, 5016-5022.

4. DiLeo, G.J.; Neff, M.E.; Savage, P.E. Gasification of guaiacol and phenol in supercritical water. Energy Fuels 2007, 21, 2340-2345.

5. Begum, S.; Rasul, M.G.; Akbar, D.; Ramzan, N. Performance analysis of an integrated fixed bed gasifier model for different biomass feedstocks. Energies 2013, 6, 6508-6524.

6. Preciado, J.E.; Ortiz-Martinez, J.J.; Gonzalez-Rivera, J.C.; Sierra-Ramirez, R.; Gordillo, G. Simulation of synthesis gas production from steam oxygen gasification of Colombian coal using Aspen Plus. Energies 2012, 5, 4924-4940.

7. Glazer, A.N.; Nikaido, H. Microbial Biotechnology: Fundamentals of Applied Microbiology, 2nd ed.; Cambridge University Press: New York, NY, USA, 2007.

8. Ahlgren, W.L. The dual-fuel strategy: An energy transition plan. Proc. IEEE 2012, 100, 3001-3052.

9. Wilhelm, D.; Simbeck, D.; Karp, A.; Dickenson, R. Syngas production for gas-to-liquid applications: Technologies, issues and outlook. Fuel Process. Technol. 2001, 71, 139-148.

10. Graschinsky, C.; Giunta, P.; Laborde, M.; Amadeo, N. Análisis Termodinámico. Producción de hidrógeno a partir del reformado autotérmico de etanol. HYFUSEN 2011. Available online: http://www.cab.cnea.gov.ar/ieds/images/2011/hyfusen_2011/trabajos/08-086.pdf (accessed on 20 May 2014).

11. Wang, H.; Wang, X.; Li, M.; Li, S.; Wang, S.; Ma, X. Thermodynamic analysis of hydrogen production from glycerol autothermal reforming. Int. J. Hydrog. Energy 2009, 34, 5683-5690.

12. Rossi, C.; Alonso, C.; Antunes, O.; Guirardello, R.; Cardozo-Filho, L. Thermodynamic analysis of steam reforming of ethanol and glycerine for hydrogen production. Int. J. Hydrog. Energy 2009, 34, 323-332.

13. Saxena, R.; Seal, D.; Kumar, S.; Goyal, H. Thermo-chemical routes for hydrogen rich gas from biomass: A review. Renew. Sustain. Energy Rev. 2008, 12, 1909-1927.

14. Rostrup-Nielsen, J. Syngas in perspective. Catal. Today 2002, 71, 243-247.

15. Tay, D.H.S.; Kheireddine, H.; Ng, D.K.S.; El-Halwagi, M.M.; Tan, R.R. Conceptual synthesis of gasification-based biorefineries using thermodynamic equilibrium optimization models. Ind. Eng. Chem. Res. 2011, 50, 10681-10695.

16. Holladay, J.E.; Bozell, J.; White, J.; Jhonson, D. Top Value Added Chemicals from Biomass-Volume II-Results of Screening for Potential Candidates from Biorefinery Lignin; Pacific Northwest National Laboratory: Richland, WA, USA, 2007.

17. Gupta; R.B.; Demirbas, A. Gasoline, Diesel and Ethanol Biofuels from Grasses and Plants; Cambridge University Press: New York, NY, USA, 2010; pp. 123-139.

18. Kumar, A.; Jones, D.D.; Hanna, M.A.; Thermochemical biomass gasification: A review of the current status of the technology. Energies 2009, 2, 556-581. 
19. Wang, Z.; Yang, J.; Li, Z.; Xiang, Y. Syngas composition study. Front. Energy Power Eng. China 2009, 3, 369-372.

20. Ravikiran, A.; Renganathan, T.; Pushpavanam, S. Generalized analysis of gasifier performance using equilibrium modeling. Ind. Eng. Chem. Res. 2012, 51, 1601-1611.

21. Guruprasad, R.; Renganathan, T.; Pushpavanam, S. Generalized thermodynamic analysis of high pressure air blown gasifier. Ind. Eng. Chem. Res. 2014, 53, 18750-18760.

22. Quintero, J.A.; Cardona, C.A. Process simulation of fuel ethanol production from lignocellulosics using aspen plus. Ind. Eng. Chem. Res. 2011, 50, 6205-6212.

23. Park, S.S.; Jeong, H.J.; Hwang, J. 3-D CFD modeling for parametric study in a 300-MWe one-stage oxygen-blown entrained-bed coal gasifier. Energies 2015, 8, 4216-4236.

24. Kuo, P.C.; Wu, W. Design, Optimization and Energetic Efficiency of Producing Hydrogen-Rich Gas from Biomass Steam Gasification. Energies 2015, 8, 94-110.

25. Weith, T.; Heberle, F.; Preißinger, M.; Brüggemann, D. Performance of siloxane mixtures in a high-temperature organic rankine cycle considering the heat transfer characteristics during Evaporation. Energies 2014, 7, 5548-5565.

26. Wu, Y.; Yang, W.; Blasiak, W. Energy and exergy analysis of high temperature agent gasification of biomass. Energies 2014, 7, 2107-2122.

27. Schefflan, R. Teach Yourself the Basic of Aspen Plus, 1st ed.; John Wiley \& Sons: Hoboken, NJ, USA, 2011; pp. 123-144.

28. Lede, J.; Lapicque, F.; Villermaux, J.; Cales, B.; Ounalli, A.J.; Anthony, M. Production of hydrogen by direct thermal decomposition of water: Preliminary investigations. Int. J. Hydrog. Energy 1982, 7, 939-950.

29. Lédé, J.; Lapicque, F.; Villermaux, J. Production of hydrogen by direct thermal decomposition of water. Int. J. Hydrog. Energy 1983, 8, 675-679.

30. Baykara, S.Z. Hydrogen production by direct solar thermal decomposition of water, possibilities for improvement of process efficiency. Int. J. Hydrog. Energy 2004, 29, 1451-1458.

31. Jellinek, H.; Kachi, H. The catalytic thermal decomposition of water and the production of hydrogen. Int. J. Hydrog. Energy 1984, 9, 667-688.

(C) 2015 by the authors; licensee MDPI, Basel, Switzerland. This article is an open access article distributed under the terms and conditions of the Creative Commons Attribution license (http://creativecommons.org/licenses/by/4.0/). 